\title{
Correction to: An ontological foundation for ocular phenotypes and rare eye diseases
}

Panagiotis I. Sergouniotis ${ }^{1 *}$, Emmanuel Maxime ${ }^{2}$, Dorothée Leroux ${ }^{3}$, Annie Olry ${ }^{2}$, Rachel Thompson ${ }^{4}$, Ana Rath², Peter N. Robinson ${ }^{5}$, Hélène Dollfus ${ }^{3,6^{*}}$ and for the ERN-EYE Ontology Study Group

\section{Correction to: Orphanet J Rare Dis \\ https://doi.org/10.1186/s13023-018-0980-6}

Professor Michael Larsen, who is a member of the ERNEYE Ontology Study Group and co-chair of Workgroup on Retinal Rare Eye Diseases (WG1), was inadvertently omitted from the author list in the Acknowledgements section of the original article [1].

\begin{abstract}
Author details
'University of Manchester and Manchester Royal Eye Hospital, Oxford Road, Manchester M13 9WL, UK. ${ }^{2}$ Orphanet, INSERM (Institut National de la Santé et de la Recherche Médicale), Paris, France. ${ }^{3}$ Centre for Rare Eye Diseases CARGO, SENSGENE FSMR Network, Strasbourg University Hospital, Strasbourg, France. ${ }^{4}$ Newcastle University, Newcastle upon Tyne, UK. ${ }^{5}$ The Jackson Laboratory for Genomic Medicine, Farmington, CT, USA. '́laboratoire de Génétique Médicale, Faculté de Médecine de Strasbourg, INSERM U1112, 11 rue Humann, 67085 Strasbourg, France.
\end{abstract}

Received: 18 July 2019 Accepted: 18 July 2019

Published online: 15 August 2019

\section{Reference}

\footnotetext{
1. Sergouniotis, et al. An ontological foundation for ocular phenotypes and rare eye diseases. Orphanet J Rare Dis. 2019;14:8 https://doi.org/10.1186/s13 023-018-0980-6.
}

\footnotetext{
* Correspondence: panagiotis.sergouniotis@manchester.ac.uk; dollfus@unistra.fr

${ }^{1}$ University of Manchester and Manchester Royal Eye Hospital, Oxford Road, Manchester M13 9WL, UK

${ }^{3}$ Centre for Rare Eye Diseases CARGO, SENSGENE FSMR Network, Strasbourg University Hospital, Strasbourg, France

Full list of author information is available at the end of the article
}

(c) The Author(s). 2019 Open Access This article is distributed under the terms of the Creative Commons Attribution 4.0 International License (http://creativecommons.org/licenses/by/4.0/), which permits unrestricted use, distribution, and reproduction in any medium, provided you give appropriate credit to the original author(s) and the source, provide a link to the Creative Commons license, and indicate if changes were made. The Creative Commons Public Domain Dedication waiver (http://creativecommons.org/publicdomain/zero/1.0/) applies to the data made available in this article, unless otherwise stated. 